\title{
Integrating Non-Friction-Based Braking Technology into \\ Locomotives to Improve Train Efficiency, Durability, and Safety \\ Christian Wanamaker
}

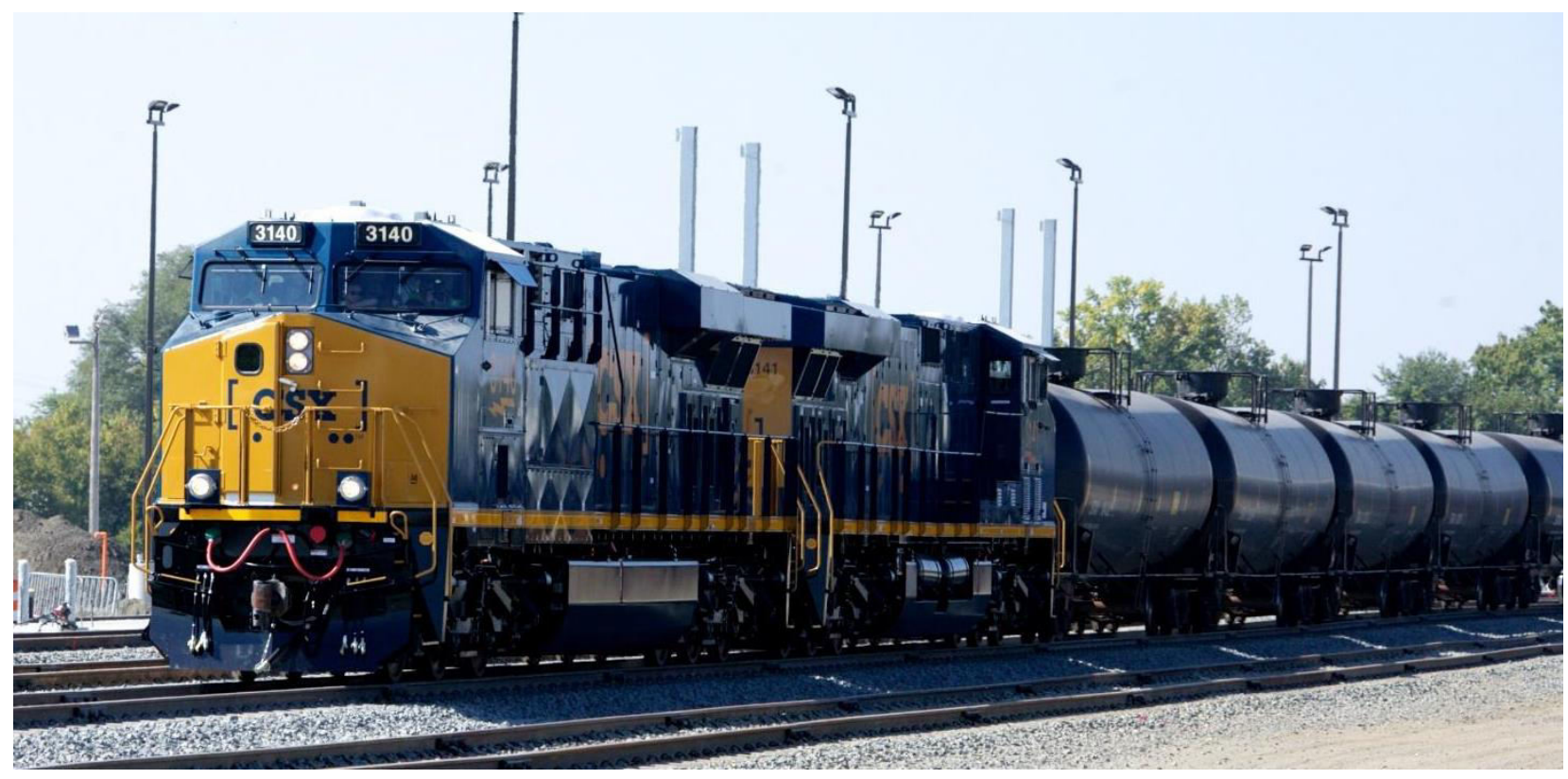

Source: stateimpact.npr.org/pennsylvania/tag/crude-by-rail/ 
Maneto: The Temple University Multi-Disciplinary Undergraduate Research Journal | 2.1

\section{Abstract}

While frictional braking is an intuitive method by which to slow vehicles, it is also a costly braking method due to the fact that frictional brakes wear down due to frequent use and high quantities of friction. On trains, this problem is worse because of their constant use and because heavier objects require stronger braking forces. The objective is to improve locomotive performance by developing a braking system that utilizes non-frictional braking technology to cut these costs and yield safer, more durable brakes. This project is directed towards dieselelectric $^{3}$ locomotives with air brakes, as engineers can design blended braking systems that integrate non-frictional braking into these braking systems. The candidate solutions include regenerative, rheostatic, and hydrodynamic braking, two of which use magnetic fields, and the third of which uses fluid drag forces. Regenerative braking is the proposed solution due to its ability to harness and use electricity during braking. Project success would contribute to railway company success by reducing expenses spent on air brakes; it would also contribute to locomotive manufacturer success because the product will likely become a popular technology. Finally, it would benefit the environment by reducing the external energy required by the railway network.

Keywords: Locomotive, braking, non-frictional, regenerative, rheostatic, hydrodynamic, diesel-electric 
Maneto: The Temple University Multi-Disciplinary Undergraduate Research Journal | 2.1

\section{Document Scenario}

This document proposes an engineering design project to provide a more durable and efficient braking method that improves upon friction-based air braking systems. I envision the document as a proposal submitted by an engineering firm to a number of locomotive manufacturers that work in close association with a public or private railway company. The technical proposal would be reviewed by engineers from the manufacturers and the railroads. The Executive Summary would be read by business managers, who would then decide whether it would be financially beneficial to fit the project's expenses within the company's budget.

\section{Executive Summary}

This goal of this project is to eliminate or reduce the problem of excessive wear, overheating, and deformation of mechanical brake blocks ${ }^{1}$ and train wheels due to the friction-based air braking process on diesel-electric locomotives. In doing so, the main focus of the project design will be on optimizing energy efficiency, cost efficiency, time efficiency, and durability of each of the components involved in the braking system, while also improving the overall safety of the train and its crew members (in addition to passengers in the case of passenger trains).

The project requires trains to be at least partially electrically powered or, at the least, to have an overhead power distribution line, in order to properly dissipate the electricity generated by the proposed braking system. An additional constraint is that the train must be either currently equipped with or compatible for installment of (a) a friction-based braking system such as the air

braking system commonly used in modern locomotives and (b) electric traction motors ${ }^{3}$ in order for the project to reach its goals for potential safety, functionality, and time efficiency concerns.

While three viable solutions to the problem are discussed in the Candidate Solutions subsection of the Problem Statement, the proposed solution offers the most overall beneficial outcome of 
the three. Not only will this solution offer a functional locomotive braking system to improve upon the air braking system, but also, it will generate electricity for the railway network at no additional cost to the company.

If successful, this project will significantly reduce overall company expenses by cutting maintenance time, labor costs, replacement costs for parts such as wheels and brake blocks, and the amount of external energy required to run the railway network. Furthermore, the project's reduction of external electricity expenditure will bring about a positive environmental impact, which will generate a positive public image of the company and ideally inspire other organizations to follow suit as well. 
Maneto: The Temple University Multi-Disciplinary Undergraduate Research Journal | 2.1

Table of Contents

$\begin{array}{ll}\text { Executive Summary } & 3\end{array}$

$\begin{array}{lr}\text { Problem Statement } & 6\end{array}$

$\begin{array}{lr}\text { Initial Problem Description } & 6\end{array}$

$\begin{array}{ll}\text { Overall Analysis and Objectives } & 7\end{array}$

$\begin{array}{lr}\text { Historical and Economic Perspectives } & 8\end{array}$

$\begin{array}{lr}\text { Candidate Solutions } & 9\end{array}$

$\begin{array}{ll}\text { Regenerative Braking } & 10\end{array}$

Rheostatic Braking 13

$\begin{array}{ll}\text { Hydrodynamic Braking } & 15\end{array}$

$\begin{array}{lr}\text { Comparison of Solutions } & 18\end{array}$

$\begin{array}{ll}\text { Proposed Solution } & 18\end{array}$

Major Design and Implementation Challenges 19

$\begin{array}{ll}\text { Implications of Project Success } & 20\end{array}$

$\begin{array}{ll}\text { Glossary } & 21\end{array}$

$\begin{array}{ll}\text { References } & 22\end{array}$ 
Maneto: The Temple University Multi-Disciplinary Undergraduate Research Journal | 2.1

\section{List of Figures}

Figure 1. Handbrakes on early trains $\quad 8$

Figure 2. Electrical current flow diagram during regenerative braking 11

Figure 3. Electrical current flow diagram between train cars 12

$\begin{array}{ll}\text { Figure 4. Locomotive resistor grid } & 13\end{array}$

Figure 5. A stator impeller (left) and rotor impeller (right) from a hydrodynamic brake 16

\section{List of Tables}

Table 1. Solution Comparison Chart 
Maneto: The Temple University Multi-Disciplinary Undergraduate Research Journal | 2.1

\section{Problem Statement}

In our rapidly innovating society, various methods of transportation continue to compete with one another with regard to time and energy efficiency. While trains are among the most prevalent mediums by which passengers and goods move from one place to another, transportation authorities and train manufacturers must continue to keep up with the increasing demand for efficiency in order for trains to remain a worthwhile method of transportation in the modern world.

\section{Initial Problem Description}

Most locomotives use friction-based air brakes as their primary braking mechanisms, which require two-stage, three-cylinder compressors to bring air to approximately $140 \mathrm{lb} / \mathrm{in}^{2}$ (psi) of gage pressure ${ }^{2}$ in a primary reservoir. The air from this reservoir is then released into brake pipes at an approximate pressure of 82.5 psi for freight cars and 100 psi for passenger cars, where the air comes into contact with a mechanical brake block (Avallone, Baumeister, \& Sadegh, 2007). The force exerted on the block by the pressurized air pushes the block against the wheel of the train, and the resultant frictional force between the block and the wheel does work on the locomotive system by converting the wheel's kinetic energy into heat, which immediately disperses into the outside air.

The frequent rubbing between the brake block, also known as brake shoe or brake block, and the train's wheel causes the block and wheel to wear down over time. The equations for wear, as supplied in the Mechanical Design Handbook, are as follows:

$$
\begin{gathered}
\text { When } T<450^{\circ} \mathrm{F}, W=P^{\alpha} V^{\beta} t \\
\text { When } T>450^{\circ} \mathrm{F}, W=P^{\alpha} V^{\beta} t e^{E / R T}
\end{gathered}
$$

In the above equations, $T=$ temperature, $W=$ weight loss in the material due to wear, $P=$ load, $V$

$=$ sliding speed, $t=$ time, $E=$ activation energy in $\frac{B t u}{m o l}, R=$ universal gas constant $=1.986 \frac{B t u}{\mathrm{~mol}^{*} R}$, 
Maneto: The Temple University Multi-Disciplinary Undergraduate Research Journal | 2.1

and $\alpha$ and $\beta$ are material-specific constants (Rothbart $\&$ Brown, 2006). Therefore, as high quantities of pressure are applied to the wheels at a moderately high velocity over a long time span, the brake blocks and wheels deteriorate quite rapidly.

Due to the wear that brake blocks and wheels experience, regular maintenance is necessary to ensure that brakes do not fail as a result of excessive wear. The need for maintenance requires companies to regularly take their trains off of the railway while the brake blocks and wheels are replaced and repaired, resulting in additional maintenance expenses for the company and fewer active trains in use on the railway network at once. An average brake block costs about $\$ 7950$ and is estimated to last 590,000 miles, resulting in an expense rate of 1.3 cents per mile (Hodges, 2012). Although 1.3 cents may not seem like much, the countless trains that travel throughout the country every day certainly add up to yield a significantly large sum of money that the industry spends on brake blocks alone every year.

\section{Overall Analysis and Objectives}

The wear of brake blocks and wheels is an especially hazardous concern when trains travel along a steep downward slope, as higher quantities of frictional work are required to keep the train from reaching dangerous speeds that could compromise the engineer's control of the train. Because of these high rates of frictional work (and the subsequent heat transfer that occurs during the process), the wheels and blocks will wear rapidly if the grade ${ }^{2}$ and distance are large enough (McGonigal, 2006). In addition, if the heat due to the friction between the brake block and wheel is produced at a faster rate than the heat's radiation into the air, then dangerous overheating occurs (Railway Technical Web Pages, 2016). Excessive wear and overheating can cause severe deformation of brake blocks and wheels, which leads to brake failure and could ultimate result in disasters such as derailment, destruction to the railway and the train, and even the deaths of passengers and workers onboard.

The main engineering objective presented in this document is to improve upon the air braking system in order to maximize efficiency, durability, and safety. While the general 
Maneto: The Temple University Multi-Disciplinary Undergraduate Research Journal | 2.1

nontechnical objective is to do so by reducing costs due to maintenance, brake/wheel replacements, and accidents (e.g. lawsuits, rail repairs, locomotive part replacements), the primary technical objective is to enhance the mechanical system's efficiency and safety by either altering its existing components, introducing additional components, or developing new mechanical/electrical systems altogether.

An ideal solution to the problem would be to coat the brake blocks and wheels in a material that never wears away, does not overheat, and requires no maintenance, but such a material does not exist. Engineers have suggested using cheaper brake blocks in order to reduce replacement costs, but (a) cheaper blocks wear quicker and therefore require more maintenance, and (b) the company would have to take trains off the railways even more frequently to perform necessary replacements and reparations (Hodges, 2012).

An effective and feasible way to solve the above problems is by integrating new braking systems that utilize a variety of non-frictional retarding forces into trains' braking systems in addition to the existing air brakes. This can greatly reduce or even eliminate the frictional work required of mechanical brake blocks, thus resulting in a multitude of improvements such as minimal maintenance and part replacement costs, far less time that trains spend inactive during maintenance, better control that engineers possess over train speed, and much greater energy efficiency. Ultimately, this will lead to the use of safer, more durable, and more efficient trains throughout the world.

\section{Historical and Economic Perspectives}

The very first train brakes required a team of brakemen, one on each car, to turn a brake wheel manually, which was connected to a simple mechanism that would force a brake block against the train's wheel. Whenever stopping or slowing was required, the conductor would blow a whistle to signal for the brakemen to apply the brakes. Not only was this task hazardous for the brakemen, who had to maneuver between cars and put their hands near heavy, fast-moving machinery, but it was also extremely dangerous for all other passengers and train personnel 
onboard. The inefficient nature of these brakes required multiple minutes and a long distance before the train could come to a complete stop, which resulted in a multitude of collisions between trains every year (European Braking Systems, n.d.).

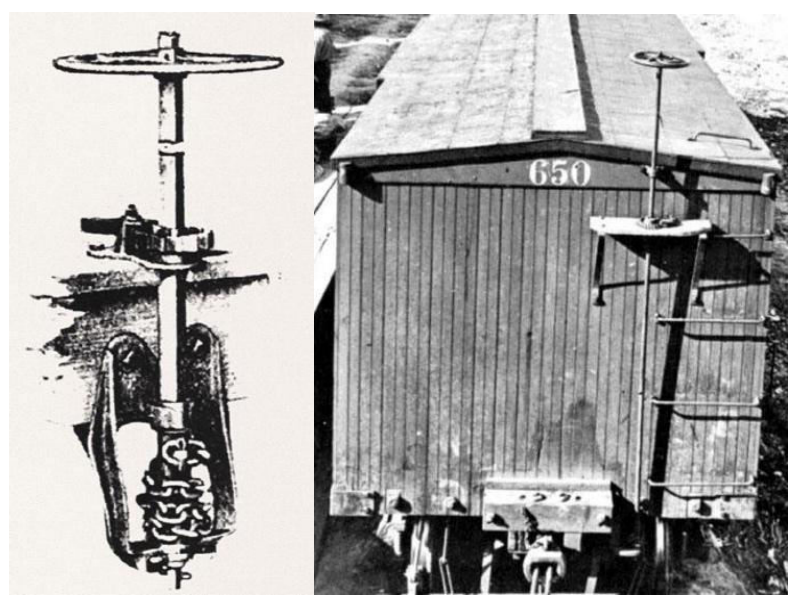

Figure 1. Handbrakes on early trains

Source: http://mrhpub.com/2013-11-nov/port/files/assets/basic-html/page219.html

In 1869, engineer George Westinghouse developed a new braking system that used pressurized air to activate all of the train's brakes simultaneously with the pull of a lever. Appropriately named the Westinghouse Air Brake, this invention included an interconnected system of air reservoirs on each train car. When the engineer would pull the brake lever, each of the reservoirs would release pressurized air into the brake cylinders and press the brake blocks against the wheels (American Rails, n.d.). While the train industry did not initially have faith in this design, Westinghouse's brake would eventually become the most commonly used braking systems around the globe. As cited by the Library of Congress, "by 1905, over 2,000,000 freight, passenger, mail, baggage and express cars and 89,000 locomotives were equipped with the Westinghouse Quick-Action Automatic Brake” (n.d.). Today, locomotives with air-powered frictional braking still use a brake design based on Westinghouse's original invention.

In the 1950s, rudimentary methods of dynamic braking were invented as diesel trains finally began to supplant the use of steam engines. The earliest form of dynamic braking was a 
Maneto: The Temple University Multi-Disciplinary Undergraduate Research Journal | 2.1

basic regenerative braking system, which rerouted the power generated from dynamic braking back into the railway's overhead line ${ }^{3}$ (OHL). In later models, this feature was not as commonly used because many modern locomotives did not support the redistribution of power back to the OHL. The main advantages that dynamic braking showcased over the air braking system were its serious reduction of required maintenance time, its ability to generate electricity to be used by other trains, better speed control, more ease of use, quicker stopping time, and the lack of the risk of overheating or deforming under too much stress (McGonigal, 2006).

\section{Candidate Solutions}

There are several methods of non-friction-based locomotive braking, but few are as common and as viable engineering solutions as the three braking types discussed in this document.

The criteria by which these systems abide are as follows:

- The solution must be a type of braking mechanism that can be used on a diesel-electric locomotive.

- The solution cannot introduce any frictional retarding forces other than the forces already established by the air brake system.

- The solution must be a part of a blended braking system, which integrates the new braking mechanism into the locomotive in order to limit the use of the existing frictional air brake system without completely replacing said system.

- The solution must be engineering-related, in that it solves the problem through a new electromechanical design or another suitable technical solution instead of a financial, institutional, or behavioral solution.

Other types of non-frictional braking systems include pneumatic braking, magneticparticle braking, and eddy-current braking. Pneumatic braking is very similar to hydrodynamic braking; the only difference is that pneumatic brakes use compressed air as the working fluid rather than a viscous liquid. Hydrodynamic brakes are a candidate solution as opposed to pneumatic brakes because the brake fluid is incompressible and therefore transmits retarding 
Maneto: The Temple University Multi-Disciplinary Undergraduate Research Journal | 2.1

forces to the wheels more immediately (Ontario Ministry of Transportation, n.d.). Magneticparticle braking is a relatively new and experimental concept, so there is not much available literature regarding (a.) experimental results or (b.) feasibility of integrating the system into existing locomotives. Eddy-current braking was once considered a viable braking method, but it was later scrapped due to the much more effective system known as regenerative braking, which is discussed below as the first candidate solution.

\section{Regenerative Braking}

Regenerative braking is a common form of electricity-based dynamic braking that generates electrical energy while braking and then repurposes said energy.

\section{Function and Application}

Trains that are equipped with electricity-based dynamic braking (such as regenerative and rheostatic braking) contain traction motors that, when switched on, generate a magnetic field called the traction-motor field (TMF), which resists the motion of the locomotive (McGonigal, 2006). As the train slows down, the resistance in the TMF causes the traction motors to absorb the train's kinetic energy via electromagnetic induction ${ }^{2}$ and convert it into electrical energy. Therefore, the traction motors in this braking system act as electrical power generators (Kutz, 2011).

The defining feature of regenerative braking, in contrast with other types of dynamic braking, is the manner in which it reroutes the electricity generated by the traction motors during braking. While many dynamic braking systems deal with this electricity as a waste product, regenerative braking systems are designed in such a way that the electricity is rerouted back into the OHL from which the locomotive derives its power (Avallone, 2007). 
Maneto: The Temple University Multi-Disciplinary Undergraduate Research Journal | 2.1

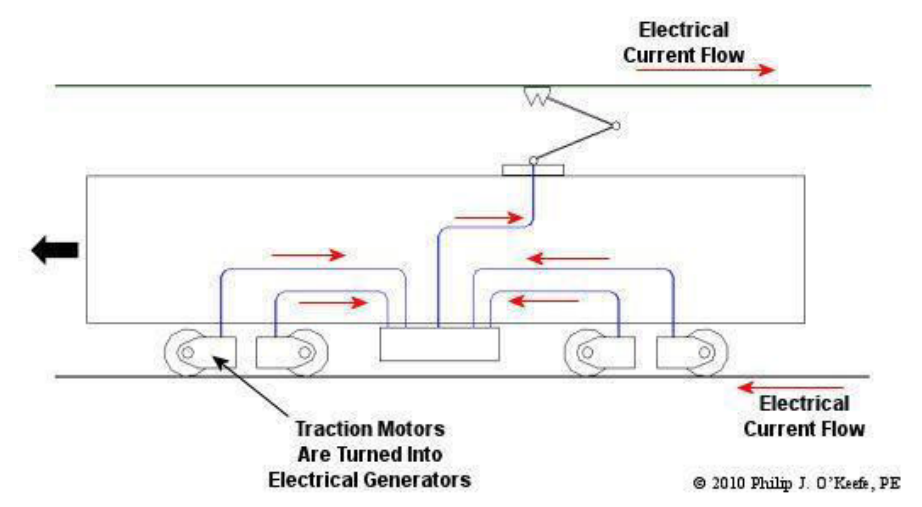

Figure 2. Electrical current flow diagram during regenerative braking

Source: http://www.engineeringexpert.net/Engineering-Expert-Witness-Blog/regenerative-brakes

\section{Benefits/Advantages}

The primary benefit of regenerative braking with respect to air braking is its ability to slow the train without the use of brake pads as it renders numerous problems such as wear, overheating, and deformation of brake pads and wheels significantly less impactful.

Regenerative braking also offers augmented train control (McGonigal, 2006) since the electric field can slow the train more promptly than brake pads can.

The main advantage that regenerative braking possesses over other types of dynamic braking is its energy efficiency. As mentioned earlier, other dynamic braking systems treat the generated electricity as a waste product, whereas regenerative braking systems reuse the electricity as another source of energy for the railway. According to the Handbook of Transportation Engineering, calculations show that regenerative braking circuits can theoretically return about 35 to $50 \%$ of the traction motors' electrical energy back to the OHL, although that number is only about $20 \%$ on modern locomotives that power numerous cars with small headways ${ }^{2}$ (Kutz, 2011).

When the electricity is rerouted to the OHL, it can then be used to supply energy to other locomotives on the railway, thus reducing the amount of external electrical energy that the railway requires to run the trains. This energy conservation ultimately saves the rail company 
money that it would have otherwise spent on additional electricity, which allows the railway company to be more environmentally friendly and economically efficient.

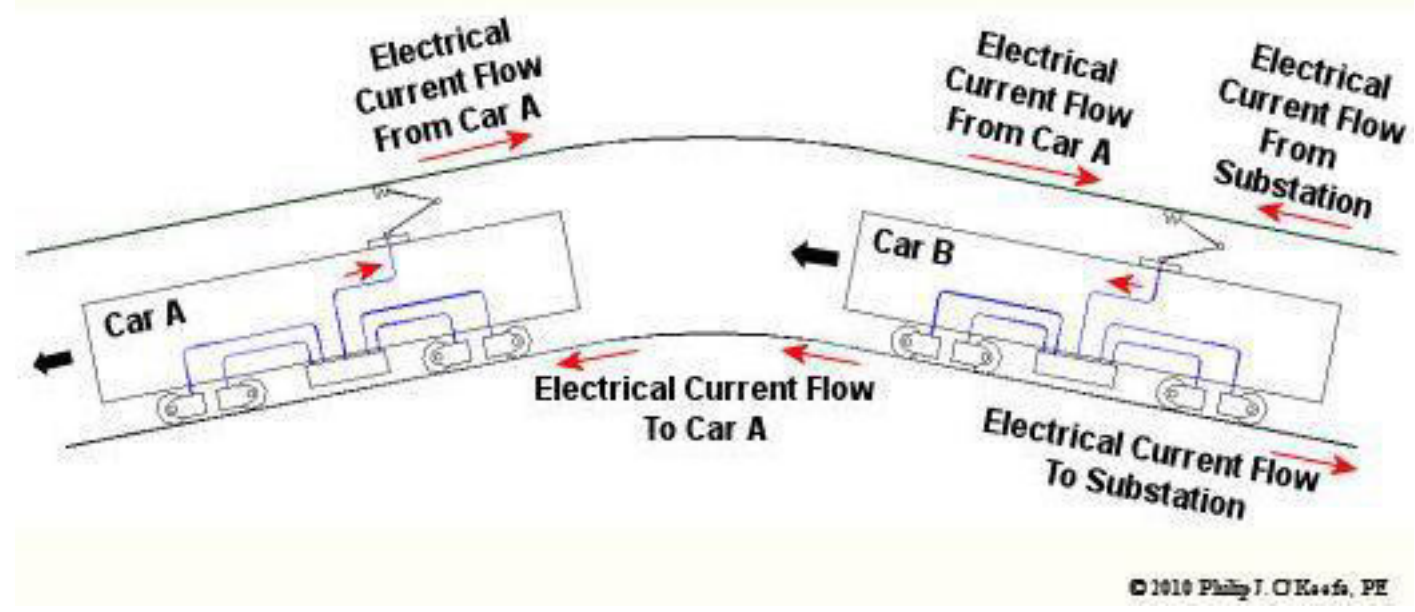

Figure 3. Electrical current flow diagram between train cars

Source: http://www.engineeringexpert.net/Engineering-Expert-Witness-Blog/regenerative-brakes

Regenerative braking is especially useful when trains need to travel up and down steep slopes. As a train travels downhill and the brakes are applied to maintain a safe velocity, the electricity that the traction motors generate is redistributed to the OHL so that other cars and trains can use the electricity to travel uphill (McGonigal, 2006).

A positive outlook about this method of braking is offered in Marks' Standard Handbook for Mechanical Engineers, which states, "It is expected that regenerative braking will become more common since energy can be returned to the line" (Avallone, 2007).

\section{Drawbacks/Disadvantages}

According to Trains Magazine, many newer types of locomotives have far more intricate circuits that cannot reroute power back to OHL (McGonigal, 2006). If someone were to reengineer the modern circuits such that two-way electricity flow between the OHL and the locomotive is enabled again, it would be a very time-consuming venture and would likely come with a high installation cost. 
Maneto: The Temple University Multi-Disciplinary Undergraduate Research Journal | 2.1

Furthermore, locomotives that utilize regenerative braking must still be equipped with air brakes or an alternative friction-based braking mechanism for two reasons. Firstly, frictional brakes are a viable backup in the event that the traction motor or accompanying circuits fail or become damaged. Secondly, frictional brakes are still frequently used to stop trains at lower speeds; Marks' Standard Handbook for Mechanical Engineers states that despite the fact that dynamic braking is highly effective when the train's velocity is between 20 and $30 \mathrm{mph}$, it is not as useful when the train is traveling under $10 \mathrm{mph}$ (Avallone, 2007).

\section{Rheostatic Braking}

Rheostatic braking is the most common form of dynamic braking - so common, in fact, that it is often simply referred to as dynamic braking, although it is only one of multiple braking types within the dynamic braking definition.

\section{Function and Application}

Rheostatic braking is similar to regenerative braking in that the locomotive contains traction motors that slow the train via a powerful TMF. However, the way in which the two systems deal with the electrical energy generated during braking differs greatly.

When the traction motors in a rheostatic braking system convert the train's kinetic energy into electrical energy, the circuit does not redistribute the energy back into the OHL. Instead, it

relays the energy to on-board resistors, which dissipate the electrical energy by slowing the flow of electrons and converting the electricity into heat (Beatty \& Fink, 2013). The resistors are laid out in a large grid, which is usually located directly underneath the roof so that the airflow caused by the locomotive's movement helps to cool the resistor grid (Kutz, 2011). 


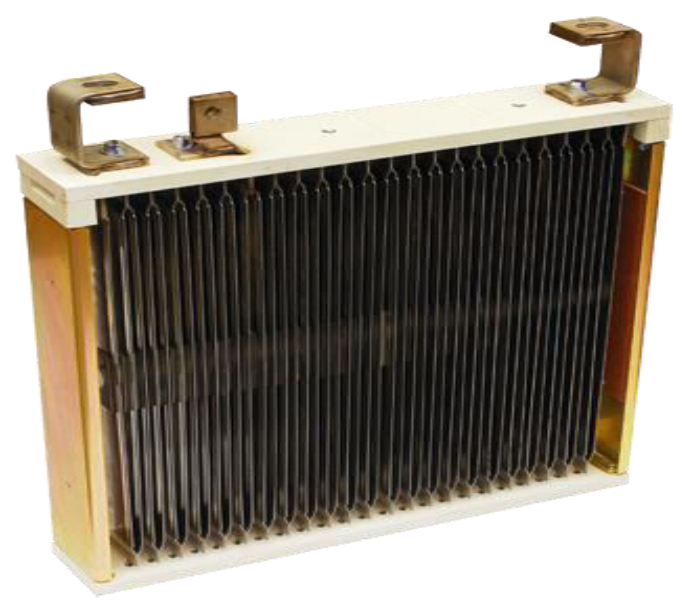

Figure 4. Locomotive resistor grid

Resistor grids such as the one pictured above are essential components in rheostatic braking systems. Source: https://www.dayton-phoenix.com/productCategoryDetail.php?categoryId=131

While electric locomotives such as those in subway trains use only ambient locomotive airflow to cool resistors, diesel-electric locomotives also use electrically powered fans to cool the resistor grid, which is still located near the roof so that the fans can blow the hot air out of ventilation hatches in the roof. Many newer locomotives include circuits that distribute some of the generated electricity due to braking to the cooling fans themselves in order to optimize energy efficiency (Avallone, 2007). Additionally, if the resistors are in danger of overheating, then the engineer can simply apply the air brakes instead of the rheostatic brake until the resistors are cool enough to continue working (Beatty, 2013).

\section{Benefits/Advantages}

Like regenerative braking, rheostatic braking solves the problem of wear, overheating, and deformation of brake blocks and wheels by greatly reducing the use of the air brake system. Another similarity to regenerative braking is the fact that rheostatic braking offers "smoother control of train speed" (Kutz, 2011).

However, an advantage that rheostatic braking has over regenerative braking is its ease of installment. As mentioned earlier, innovations in locomotives' electrical systems often prohibit the rerouting of power to the OHL (McGonigal, 2006), so it would require a great deal of time 
Maneto: The Temple University Multi-Disciplinary Undergraduate Research Journal | 2.1

and money to design and build newer electrical systems in order to re-enable regenerative braking. Rheostatic braking, on the other hand, does not require redistribution of power back through a pre-established circuit, so existing circuits do not need to be greatly altered. The only additional components that are needed are a resistor grid, a ventilation system, and the wiring required to properly channel the electricity to the resistors and fans - all of which can be installed aboard the train.

Although it does not repurpose as much electricity as regenerative braking does, rheostatic braking still puts some of its post-traction-motor electricity to use, as exhibited by the aforementioned cooling fan feature. Since this electricity can be harnessed to power a series of simple cooling fans, it is plausible that other appliances such as headlights, ceiling lights in passenger cars, and wall outlets could be powered in a similar way, thus increasing the braking system's potential for electrical energy conservation.

Lastly, some locomotives with rheostatic braking also have "“extended range' dynamic braking, which enables these locomotives to use dynamic braking at speeds as low as $3 \mathrm{mi} / \mathrm{h}$ " (Avallone, 2007). This feature is beneficial because it further limits the locomotive's use of air brakes.

\section{Drawbacks/Disadvantages}

The main drawback of rheostatic braking is its inefficiency relative to other forms of electrically-based dynamic braking, especially regenerative braking, since the electrical energy generated via rheostatic braking is dissipated as heat in resistors (and as kinetic energy in fans to cool these resistors) instead of utilized for other purposes. That being said, it is still plausible to repurpose this energy onboard, but since it has not been done yet, there is no available literature to prove the claim.

Moreover, due to the resistors' tendency to overheat as a result of extreme stress, locomotives with rheostatic braking systems will have to use their air brakes more frequently, thus increasing the wear of the train's wheels and brake blocks (Beatty, 2013). 
Maneto: The Temple University Multi-Disciplinary Undergraduate Research Journal | 2.1

\section{Hydrodynamic Braking}

While hydrodynamic braking does not involve the use of electrically-generated magnetic fields to slow the train, it still utilizes advanced methods beyond the simple frictional force of a brake block against a wheel to decrease the kinetic energy of the train. Also, its benefits and drawbacks are closely comparable to that of regenerative and rheostatic ( $\& \& R)$ braking, making it a viable third solution for consideration.

\section{Function and Application}

As stated by C.Y. Wang, the hydrodynamic brakes, also known as hydrodynamic retarders, on a locomotive each consist of two parallel, disk-shaped plates, also called impeller, with a highly viscous fluid in between them. One of the plates, called the rotor, is cocentrically ${ }^{2}$ connected to the train's wheel and rotates at the same angular velocity as the wheel, while the other plate, or the stator, is held stationary with a relative angular velocity of 0 . When compressed, the fluid between the plates resists the rotation of the wheel, as the hydrodynamic drag between the fluid and the rotating plate causes a viscous torque that opposes the rotation of the wheel (Wang, 1985). Through this process, the hydrodynamic brake converts the kinetic energy of the train into heat, which is transferred from the rotating plate to the fluid. The thermal energy of the fluid is then transferred to a coolant such as oil, transmission fluid, or subcooled ${ }^{3}$ water, which can either be pumped through the locomotive's radiator or through an individual, car-mounted cooling mechanism (Xin, 2011).

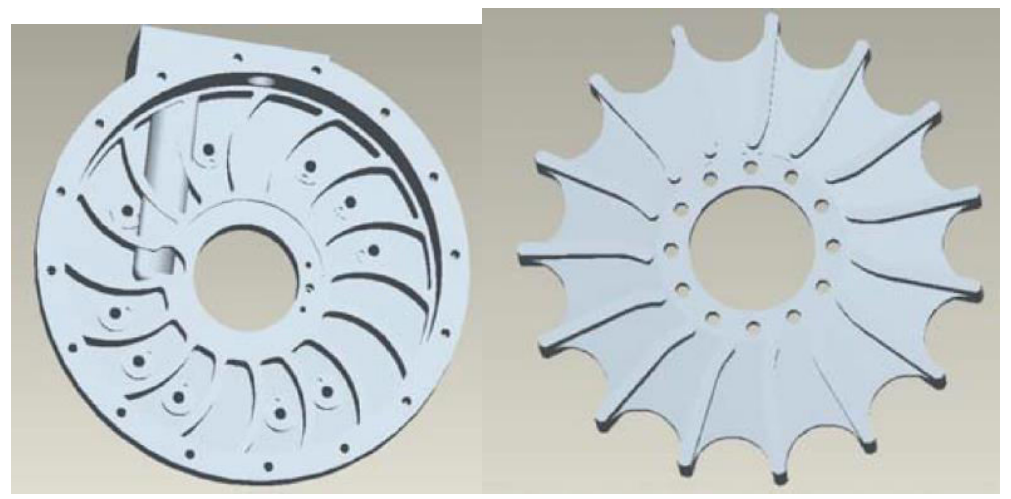

Figure 5. A stator impeller (left) and rotor impeller (right) from a hydrodynamic brake

Source: http://ieeexplore.ieee.org/stamp/stamp.jsp?arnumber=6199419 
Maneto: The Temple University Multi-Disciplinary Undergraduate Research Journal | 2.1

Diesel Engine System Design states that the engineer can increase or decrease the braking power of hydrodynamic brakes by either raising or lowering the pressure of the hydrodynamic fluid. This is true because of the relationship between pressure and retarding torque; as the pressure of the fluid increases, the torque increases along with it. That being said, the limiting factor regarding the amount of braking torque that can be generated is the heat flow rate between the tire, hydrodynamic fluid, and the coolant (Xin, 2011). In other words, the hydrodynamic brakes can only remove as much kinetic energy from the train as the coolant can remove thermal energy from the fluid; thus, it is of utmost importance that the cooling system works properly in order to avoid overheating of the braking fluid.

\section{Benefits/Advantages}

A primary benefit that hydrodynamic braking shares with $R \& R$ braking is its wear reduction, for "solid-to-solid contact" (Wang, 1985) is avoided during the hydrodynamic braking process. Hydrodynamic braking augments train control about the same amount as R\&R braking (Xin, 2011). Furthermore, the braking fluid inside of the hydrodynamic brake is very easy to replace in comparison to frictional brake blocks (Wang, 1985).

Hydrodynamic brakes are exceptionally durable and they can produce up to twice as much power as the diesel locomotive can produce, which is a far greater rate than the braking power exhibited by R\&R braking. Hydrodynamic braking is also more effective at higher speeds (Xin, 2011), whereas electromagnetic dynamic braking types are not as effective at speeds greater than $30 \mathrm{mph}$ (Avallone, 2007).

Finally, according to Qianfan Xin, "savings from the increased brake lining life, reduced long-term maintenance cost, less down-time, shorter travel time and the elimination of damage and injury due to a brake-failure accident usually exceed the cost of the retarder" (Xin, 2011), which proves that hydrodynamic brakes are not only an effective braking method, but also a financially sensible decision.

\section{Drawbacks/Disadvantages}

When hydrodynamic brakes produce such a large amount of braking power, they also expel heat at exceptionally high rates, and it is very difficult to implement a cooling system that 
Maneto: The Temple University Multi-Disciplinary Undergraduate Research Journal | 2.1

can keep up with this high rate of heat exchange. In addition, the brakes themselves are cited as "heavy, large, and expensive" (Xin, 2011), so even though the brakes may pay themselves off over time, hydrodynamic braking systems are still quite a hefty investment at the start.

A common drawback that hydrodynamic brakes share with other forms of dynamic braking is their ineffectiveness at low speeds. Since they are designed to handle tasks that require large amounts of braking power, they cannot actually bring the train to a full stop on their own (Hicks, 2006), which is why they must be integrated into a blended braking system with air brakes or other frictional brakes, which are then used to stop the train completely once it reaches a much lower speed.

There are two other serious drawbacks with hydrodynamic braking as opposed to $R \& R$ braking, the first of which is a slight delay in response time. While air brakes and R\&R brakes act almost instantaneously upon the pull of a lever or the flip of a switch, hydrodynamic brakes require about 0.2 seconds to activate and 0.1 seconds to release (Xin, 2011) because the plates must compress the fluid before the viscous torque can have any significant effect on train speed. Although 0.2 seconds does not seem like a serious activation delay, it could potentially be the difference between safety and a dangerous accident in an emergency situation. However, the brakes' response time can be reduced if engineers can find an effective way to minimize the volume of the retarders without compromising the effects of the viscous torque (Xin, 2011). Finally, according to a journal article by M. Jahn (as cited in Xin, 2011), hydrodynamic braking energy efficiency is slightly less than that of R\&R braking due to the fact that the brakes expend small amounts of energy while the train is idling. 


\title{
Comparison of Solutions
}

\author{
Table 1. Solution Comparison Chart
}

\begin{tabular}{|c|c|c|c|}
\hline & Regenerative Braking & Rheostatic Braking & Hydrodynamic Braking \\
\hline Energy Efficiency & $\begin{array}{l}\text { High efficiency ( } 20 \% \text { of } \\
\text { energy is reused) }\end{array}$ & $\begin{array}{l}\text { Moderate efficiency (small } \\
\text { amounts of energy reused) }\end{array}$ & $\begin{array}{l}\text { Slightly less than moderate due } \\
\text { to energy loss during idling }\end{array}$ \\
\hline $\begin{array}{l}\text { Installation Cost/Ease } \\
\text { (Cost Efficiency) }\end{array}$ & $\begin{array}{l}\text { High cost, difficult to } \\
\text { integrate into modern } \\
\text { locomotives because of } \\
\text { complex one-way circuits }\end{array}$ & $\begin{array}{l}\text { Moderate cost, easy to } \\
\text { install because all hardware } \\
\text { can be set up inside the } \\
\text { locomotive }\end{array}$ & $\begin{array}{l}\text { High cost, difficult to install } \\
\text { due to necessary high-strength } \\
\text { cooling system (but eventually } \\
\text { pays itself off) }\end{array}$ \\
\hline $\begin{array}{l}\text { Maintenance Reduction } \\
\text { (Time Efficiency) }\end{array}$ & Large reduction & Large reduction & $\begin{array}{l}\text { Significant reduction, but } \\
\text { minimal time is required to } \\
\text { replace brake fluid }\end{array}$ \\
\hline $\begin{array}{l}\text { Wear Reduction } \\
\text { (Durability) }\end{array}$ & Very large wear reduction & Very large wear reduction & Very large wear reduction \\
\hline Train Control (Safety) & Significant increase in control & $\begin{array}{l}\text { Significant increase in } \\
\text { control }\end{array}$ & High increase in control \\
\hline Environmental Impact & $\begin{array}{l}\text { Positive impact due to } \\
\text { recycling of energy }\end{array}$ & $\begin{array}{l}\text { Minimal impact due to } \\
\text { minimal repurposing of } \\
\text { energy }\end{array}$ & $\begin{array}{l}\text { No impact, aside from } \\
\text { reducing the production of } \\
\text { brake blocks }\end{array}$ \\
\hline Response Time & Instantaneous & Instantaneous & $\begin{array}{l}0.2 \text { seconds to activate, } \\
0.1 \text { seconds to deactivate }\end{array}$ \\
\hline
\end{tabular}

\section{Proposed Solution}

As described in the "Benefits/Advantages" and "Drawbacks/Disadvantages" subsections included in each candidate solution (and consolidated in Table 1), each of the three candidate solutions has its own strengths and weaknesses relative to the other two, so the most desirable solution ultimately comes down to how each factor is prioritized and weighed. For instance, if the locomotive manufacturers and railway companies strongly favor train control over the other 
Maneto: The Temple University Multi-Disciplinary Undergraduate Research Journal | 2.1

factors discussed in Table 1, then hydrodynamic braking would be the most ideal solution. The factors are arranged in descending order of importance and relevance to the overall engineering objective in an effort to illustrate the priority level of each benefit and drawback, thereby easing the decision process and clarifying the reasoning behind the proposed solution choice.

Since energy, cost, and time efficiency are ultimately the most crucial factors with regard to improving modern transportation systems, hydrodynamic braking has been ruled out due to its high installation cost, lower energy efficiency relative to electrically-powered dynamic braking, and greater amount of regular maintenance required. While it certainly offers more comprehensive speed control than R\&R braking, the enhanced speed control that it does boast comes at a cost (i.e. it requires powerful cooling mechanisms to act upon the hydraulic fluid in order to maintain braking power). It simply does not outweigh the economically beneficial features exhibited by R\&R braking, which still greatly improve upon the speed control capabilities of air brakes.

This leads to the decision between regenerative braking and rheostatic braking. The main advantage that rheostatic braking possesses over regenerative braking is its ease of installment, as it does not require the re-engineering of the circuits that connect the OHL to the locomotive's traction motors. Beyond installment cost and ease, however, regenerative braking boasts an additional 20\% energy efficiency over rheostatic braking (Kutz, 2011), which will very quickly pay off the installation and redesign costs and will continue to save the railway money with further use.

The regenerative braking system solves each of the main issues laid out in the Initial Problem Description and accomplishes all of the goals set in the Overall Analysis and Objectives section. Firstly, it greatly reduces the use of the friction-based air brake system, which exponentially extends the lifetime of mechanical brake blocks and train wheels. This saves the railway valuable time that would have otherwise been spent on maintaining and replacing these brake blocks and wheels, in addition to relieving the financial burden of numerous wheel and brake block replacements. Secondly, it greatly improves train safety by enhancing the engineer's control over train speed, preventing overheating and subsequent deformation of brake blocks and wheels, and exhibiting an instantaneous response time. Finally, it is highly energy efficient, as it 
Maneto: The Temple University Multi-Disciplinary Undergraduate Research Journal | 2.1

repurposes $20 \%$ of the electrical energy generated during braking, which is often useful in helping other trains or cars climb large grades (McGonigal, 2006).

\section{Major Design and Implementation Challenges}

There are two serious hurdles that engineers must overcome in order to undergo successful design and implementation of a regenerative braking system in more modern dieselelectric locomotives. The main obstacle is to modify the circuits that transmit electricity between the OHL and the locomotive because most new locomotives do not support the re-routing of electricity back through the same supply wire like many older models do. The second challenge is to improve the wiring system so that it can transmit even more of its post-traction-motor electricity back to the OHL in order to conserve more energy, save railways more money, and reduce the environmental impact of rail-based transportation.

Since it would be counterintuitive to replace newer, more advanced wiring systems that transfer electricity from the OHL to the traction motors with the older regenerative braking circuit designs, I would suggest installing an additional pantograph ${ }^{3}$ on top of the train to relay electricity back into the OHL. This would act as an exit path for excess electricity, and it would be much simpler than trying to re-work the old two-way power pantographs as shown in Figures 2 and 3. This would still pose a challenge because it would require additional hardware, wiring, and labor to set up the new pantographs, but it would ultimately be worthwhile if it eases the flow of electricity between the locomotive and the OHL.

The second design challenge, although not an absolute necessity, would be immensely beneficial if proven to be a successful endeavor. While formulating the new design, engineers should aim to keep the resistance of the post-traction-motor circuit as low as possible in order to repurpose as much energy as possible. The Handbook of Transportation Engineering states that the theoretical efficiency of many regenerative braking systems can range from $35 \%$ to $50 \%$ (Kutz, 2011), so it is reasonable to infer that upon minimizing the resistance of the circuit and the 
Maneto: The Temple University Multi-Disciplinary Undergraduate Research Journal | 2.1

overall length of wiring from the traction motors to the OHL would bring the $20 \%$ efficiency somewhere closer to $30 \%$.

\section{Implications of Project Success}

If this project is successful, then the railway companies investing in this technology will notice far fewer annual expenses on electricity. As a result, railways that offer transportation could potentially lower their ticket prices to gain a competitive edge on other transportation companies. Additionally, project success will lead to other railways that will be interested in regenerative braking systems, resulting in more business for the locomotive manufacturers who choose to utilize this technology.

Popularity and success of regenerative braking will also lead to a smaller demand for brake block and wheel replacements, though the demand will still exist as long as blended braking systems are still commonly used. Finally, project success will cause a sizable decrease in railways' electrical energy consumption, which will ultimately yield a positive environmental impact, and ideally, the tides of renewable energy sources will continue to surge forward in an effort to preserve the environment and lead to a more efficient global society. 


\section{Glossary}

Brake block $^{1}$ : a block of hard material pressed against the rim of a wheel to slow it down by friction

Cocentric $^{2}$ : having a common central axis

Diesel-electric $^{3}$ : a type of locomotive that contains a diesel engine that drives an electric generator, which provides power to the traction motors that drive the locomotive

Electromagnetic induction ${ }^{2}$ : the induction of an electromotive force in a circuit by varying the magnetic flux linked with the circuit

Gage pressure $^{2}$ : the pressure at a point in a fluid above to that of the atmosphere

Grade $^{2}$ : a degree of inclination of a road or slope

Headway $^{2}$ : the time between two vehicles [e.g. train cars] traveling in the same direction on the same route

Overhead line $\mathrm{S}^{3}$ (OHL): a suspended wire along a railway used to transmit electrical energy to trains

Pantograph $^{3}$ : the device which maintains electrical contact with the OHL and transmits power from the line to the train

Subcooled $^{3}$ : the state wherein a fluid is at a temperature below its freezing point but remains a liquid because of mechanical or thermodynamic conditions that force it to remain as such

Traction motor ${ }^{3}$ : an electric motor used for propulsion of a vehicle

\footnotetext{
${ }^{1}$ www.google.com

${ }^{2}$ www.merriam-webster.com

${ }^{3}$ www.wikipedia.com
} 
Maneto: The Temple University Multi-Disciplinary Undergraduate Research Journal | 2.1

\section{References}

American Rails (n.d.). The Westinghouse Automatic Air Brake. Retrieved from http://www.americanrails.com/westinghouse.html\#Top

Avallone, Eugene A., Theodore Baumeister III, and Ali Sadegh. 2007. Marks' Standard Handbook for Mechanical Engineers, Eleventh Edition. New York, NY: McGraw-Hill.

Beatty, H. Wayne, and Donald G. Fink. 2013. Standard Handbook for Electrical Engineers, Sixteenth Edition. New York, NY: McGraw-Hill.

European Braking Systems (n.d.). History of Air Braking. Retrieved from https://www.europeanbrakingsystems.co.uk/history

Hicks, Tyler G. 2006. Handbook of Mechanical Engineering Calculations, Second Edition. New York, NY: McGraw-Hill.

Hodges, Tim. (2012, April 20). A Life-Cycle Approach to Braking Costs. International Railway Journal. Retrieved from http://www.railjournal.com/index.php/rolling-stock/a-life-cycle-approach-tobraking-costs.html

Kutz, Myer. 2011. Handbook of Transportation Engineering, Volume II: Applications and Technologies, Second Edition. New York, NY: McGraw-Hill.

Library of Congress (n.d.). The Westinghouse Air Brake Co. Retrieved from https://www.loc.gov/collections/films-of-westinghouse-works-1904/articles-and-essays/thewestinghouse-world/the-westinghouse-air-brake-co/

McGonigal, Robert S. (2006, May 1). Dynamic Braking: Power for the (Down) Grade. Trains Magazine. Retrieved from http://trn.trains.com/railroads/abcs-of-railroading/2006/05/dynamic-braking

Ontario Ministry of Transportation (16 March 2019). Vehicle Braking Systems. Retrieved from

Railway Technical Web Pages (17 November 2016). Train Braking Glossary. Retrieved from http://www.railway-technical.com/brake1.shtml

Rothbart, Harold, and Thomas H. Brown. 2006. Mechanical Design Handbook, Second Edition: Measurement, Analysis, and Control of Dynamic Systems. New York, NY: McGraw-Hill. 
Maneto: The Temple University Multi-Disciplinary Undergraduate Research Journal | 2.1

Wang, C.Y. (1985). Hydrodynamic Disk Braking. Journal of Applied Disk Braking, 52, 263-266. doi: $10.1115 / 1.3169038$

Xin, Qianfan. 2011. Diesel Engine System Design. Sawston, England: Woodhead Publishing. 